\title{
Valuation of defined benefit pension schemes in IAS 19 employee benefits - true and fair?
}

Bridget McNally

Maynooth University, Maynooth, Ireland

\author{
Anne M. Garvey \\ Universidad de Alcala, Madrid, Spain, and \\ Thomas O'Connor \\ Maynooth University, Maynooth, Ireland
}

\begin{abstract}
Purpose - This paper aims to argue that the accounting standards' requirements for the valuation of defined benefit pension schemes in the financial statements of scheme sponsoring companies potentially produce an artificial result which is at odds with the "faithful representation" and "relevance" objectives of these standards.

Design/methodology/approach - The approach is a theoretical analysis of the relevant reporting standards with the use of a practical example to demonstrate the impact where trustees adopt a hedged approach to portfolio investment.

Findings - Where a pension fund engages in asset liability matching and invests in "risk-free" assets, the term, quantity and duration/maturity of which is intended to match some or all of its scheme liabilities, the required accounting treatment potentially results in the sponsoring company's financial statements reporting fluctuating surpluses or deficits each year which are potentially ill informed and misleading.

Originality/value - Pension scheme surpluses or deficits reported in the financial statements of listed companies are potentially very significant numbers; however, the dangers posed by theoretical nature of the calculation have largely gone unreported.
\end{abstract}

Keywords Hedging, Relevance, Faithful representation, Risk free assets

Paper type Research paper

\section{Introduction}

This paper argues that the accounting standards' requirement for the valuation of Defined Benefit pension schemes in the financial statements of scheme sponsoring companies, produces an artificial result which is at odds with the "faithful representation" and "relevance" objectives of these standards and the overriding objective of enabling users of Financial Statements to receive high- quality understandable financial reporting proportionate to the size and complexity of the entity and users' information needs.

Accounting for defined benefit plans in the financial statements of the sponsoring company is a complex matter. The complexity arises because the employer must, in each accounting period, recognize as an expense in its income statement/profit and loss account the cost to the employer of the retirement benefits that will eventually be paid to employees because of the services that they have provided during the period. Because these benefits may be payable in many years' time and their cost will depend on a number of factors (e.g. mortality, return on investments), which are difficult to determine in advance, the

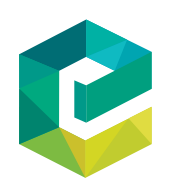

Journal of Financial Regulation and Compliance Vol. 27 No. 1, 2019 
JFRC 27,1

calculation of the expense which should be recognized in an accounting period is not straightforward. As the sponsoring company carries the risk of any shortfall arising on a defined benefit scheme (i.e. if amounts contributed by both the employer and the employee, together with the net investment return on such contributions were insufficient to pay the scheme pensions and benefits as they fall due), such a shortfall if it were to exist, would constitute a medium to long term liability of the sponsoring company, over and above its annual funding commitment. This shortfall would need to be recognized as such in the sponsoring company's financial statements. The converse also applies in that any excess of assets in the pension scheme (i.e. surplus) which could reduce the sponsoring company's payments or commitments in the future would (providing certain criteria are met) also be required to be recognized as an asset in its financial statements.

For Irish and UK entities (depending on the entity concerned), the preparation and presentation of these financial statements is governed by International Financial Reporting Standards (IFRS) or in accordance with the provisions of domestic accounting standards (FRS 100-102 and FRSSE). Under both sets of standards, a complete set of financial statements includes a Statement of Financial Position (SOFP) (Balance Sheet), a Statement of Profit and Loss and Other Comprehensive Income (Profit and Loss A/C), a Statement of Changes in Equity, a Statement of Cash Flows, and Accounting Policies and Explanatory Notes.

IFRS are issued by the International Accounting Standards Board (IASB), which seeks to harmonize regulations, accounting standards (IFRS) and procedures relating to the preparation and presentation of financial statements. Its stated belief is that financial statements, which are prepared for the purpose of providing information which is useful in making economic decisions, should meet the common needs of most users. This is because nearly all users are making economic decisions, for example, to decide when to buy, hold or sell an equity investment; to assess the stewardship or accountability of management; to assess the ability of the entity to pay and provide other benefits to employees; to assess the security for amounts lent to the entity; to determine taxation policies; to determine distributable profits and dividends; to prepare and use national income statistics; and to regulate the activities of entities.

The IASB adopts a principles based approach to standard setting and underlying this principles based approach is a "Conceptual Framework" (CF) developed by the IASB, which sets out the concepts that should underlie the preparation and presentation of financial statements for external users. Among the stated objectives of the CF are; to assist the Board in the development of future IFRSs and in its review of existing IFRSs; to assist the Board in the harmonization of regulations, accounting standards and procedures relating to the presentation of financial statements by providing a basis for reducing the number of alternative accounting treatments permitted by (IFRS); to assist preparers of financial statements in applying IFRSs and in dealing with topics that have yet to form the subject of an IFRS; to assist auditors in forming an opinion on whether financial statements comply with IFRSs; and to assist users of financial statements in interpreting the information contained in financial statements prepared in compliance with IFRS.

The CF recognizes two fundamental characteristics of useful information; relevance and faithful representation. Information is relevant if it is capable of making a difference to a decision. It should have predictive value, confirmatory value or both. To "faithfully represent" the position and performance of a reporting entity for a financial period, financial statements should be complete, neutral and free from error. Materiality is an entity specific aspect of relevance. Recognition of "substance over form" is incorporated in the "faithful representation" of transactions and events. 
FRS 102, effective for accounting periods beginning on or after 1 January 2015 is a single reporting standard that applies(subject to certain exceptions) to the financial statements of all UK and Republic of Ireland entities that are not applying EU adopted IFRS. This includes entities not constituted as companies and those that are not profit-orientated. The company law maxim of "true and fair" is replaced in FRS102 by terms such as "fair presentation" and "faithful representation"; however, the underlying sentiment remains. The objective of financial statements within the scope of the FRS is:

To provide information about the financial position, performance and cash flows of an entity that is useful for economic decision- making by a broad range of users who are not in a position to demand reports tailored to meet their particular information needs (FRS102, p. 11).

The FRS sets out a number of concepts and pervasive principles, which should underlie the information in financial statements. Amongst other criteria, the information provided in financial statements must be relevant to the decision-making needs of users. This means it must be:

Capable of influencing the economic decisions of users by helping them evaluate past, present or future events or confirming or correcting their past evaluations (See FRS102 p. 11).

The remainder of this paper is structured as follows. Section 2 looks at the accounting standards requirements for the valuation of pension scheme commitments in the sponsoring company's financial statements. Section 3 considers these requirements within the context of the overriding objective of the $\mathrm{CF}$ for relevance and fair representation in financial statements. Section 4 provides some indication of the wealth of discussion in the literature as to what the appropriate discount rate might be for pension scheme liabilities, and Sections 5 and 6 extend the discussion to consideration of the particular anomalies arising where the pension scheme liabilities may be hedged. Section 6 uses a theoretical example to highlight the practical impact of the current accounting treatment on financial statement reporting and questions the relevance and faithful representation of the results produced. Finally, Section 7 includes some concluding remarks.

\section{Review of accounting standards IAS 19 and FRS 102 in relation to pension reporting}

International Accounting Standard No. 19 (IAS 19) (International Accounting Standards Board, 2011) provides the internationally recognized guidance on accounting for and disclosure in Financial Statements of defined benefit pension benefits and obligations. The first stated objective of IAS 19 is to ensure that an employer's SOFP reflects a net pension liability/asset in respect of employee benefits to be paid in the future. The second stated objective of IAS 19 is to ensure that the employer's Statement of Profit or Loss and Other Comprehensive Income(SPLOCI) recognizes an expense when the employer consumes an economic benefit arising from the services provided by the employee in exchange for employee benefits.

Accounting for defined benefit plans is complex because actuarial assumptions and valuation methods are required to measure the SOFP obligation and the SPLOCI expense. The plan liabilities (the defined benefit obligation) and the plan assets are measured at each reporting year-end date. The plan assets are measured at fair value (not necessarily the same as either "net realizable value" or market value). The defined benefit obligation is measured on an actuarial basis and discounted to present value. The difference between the fair value of the plan assets and the present value of the defined benefit obligation is a surplus or deficit. A surplus is an asset to the extent that the employer gains an economic benefit from 
it. A deficit is a liability to the extent that the employer has a legal or constructive obligation to make it good. It is the accrued net cost to date at the reporting year-end date (over and above the employers' normal contribution rate) of the promise inherent in a defined benefit scheme that the employer will make good any shortfall in the schemes funding. Subject to certain conditions, a surplus or deficit is recognized as appropriate as an asset or liability on the employer's SOFP.

IAS 19 requires the surplus or deficit as calculated to be recognized in the employer company's SOFP as a defined benefit liability (deficit) or asset (surplus). The deficit/surplus is the present value of the defined benefit obligation at the SOFP date minus the fair value at the SOFP date of plan assets out of which the defined benefit obligation is to be settled directly.

The defined benefit obligation is defined as reflecting, "expected future payments required to settle the obligation resulting from employee service in the current and prior periods". It comprises not only legal obligations under the formal terms of the plan, but also constructive obligations arising from the employer's informal practices, e.g. an established practice of facilitating early retirement even though this may not be specifically provided for in the terms of the scheme. The calculation of the liability includes a projection of the benefit earned to date to each future point that the benefit could be paid with allowance for salary increases and probabilities of payment. This requires assumptions on mortality, both during and after employment, rates of employee turnover, disability and early retirement, the proportion of plan members with dependents who will be eligible for benefits. The liability must then be discounted back to the current valuation date using the yield on high quality corporate bonds (AA).

For Irish and UK entities, not applying IFRS, S.28 of FRS 102 sets out the applicable accounting treatment for employee benefits, including post-employment benefits in the form of defined benefit and defined contribution pensions. The requirements are strongly consistent with the provisions of IAS 19 requiring recognition of the "net defined benefit liability" and the net change in that liability during the period as the cost of the defined benefit plan for the period. The "net defined benefit liability is the net total of the obligations under the defined benefit plan minus the fair value at the reporting date of the plan assets out of which the obligations are to be settled. An entity is required to measure its defined benefit obligation on a discounted present value basis:

The entity shall determine the rate used to discount the future payments by reference to market yields at the reporting date on high quality corporate bonds. In countries with no deep market in such bonds, the entity shall use the market yields (at the reporting date) on government bonds. The currency and term of the corporate bonds or government bonds shall be consistent with the currency and estimated period of the future payments (See FRS 102, p. 171).

\section{IAS 19 and FRS 102 and the overarching requirement for relevance and faithful representation}

This paper argues that the IAS 19/FRS102 requirement for scheme liabilities, to be discounted in the first instance by reference to market yields on high quality corporate bonds even in instances where the pension scheme has engaged in hedging/asset liability matching, potentially produces a result which is at odds with the "relevance" and "faithful representation" objectives of these standards and the overriding objective of enabling users of accounts to receive high-quality understandable financial reporting. The effect of IAS 19/FRS102 where pension scheme liabilities are hedged by "risk free" assets with matching maturity amounts is to discount the relevant assets and liabilities at potentially different discount rates. The result 
cannot be regarded as having a predictive value or a confirmatory value, which is useful to users given that it is based on theoretical assumptions and calculations and the reality of the hedged contracts and arrangements is ignored.

It is accepted that in recent years there has been a growing interest in the management of pension funds and the need for a more professional management of the relationship between the assets and liabilities of a pension fund. This paper demonstrates that the effect of IAS 19/FRS102 is to mask the risk management impact of any hedging strategies undertaken by a pension fund in the reported results of the sponsoring company. In striving to reduce the

Defined benefit pension schemes amounts, which are neither true nor fair nor relevant.

\section{Don't discount the discount rate}

The question of what discount rate should be used to value defined benefit pension liabilities and the resultant impact on defined benefit pension accounting and firm valuations continue to warrant and attract research analysis despite ongoing changes to accounting and actuarial practice. Khorasanee (2004) concludes there is an acceptance that the use of discount rates linked to corporate bond yields rather than government issued index linked bonds to measure pension liabilities allows for the risk of default. However, the author contends that the use of an AA corporate bond discount rate for different companies is an ad-hoc approach, which does not attempt to allow for variations in default risk for different companies.

Coronado et al. (2008) consider the difficulties in properly valuing firms that sponsor DB plans. The author's examination spanned a period of stock market boom and bust which would have heightened the attention of stock market analysts and policymakers to the impact of equity prices on net pension fund balances in financial statements. The authors conclude that firm valuations continue to be unduly influenced by what is reported in firm income statements while little weight is placed on the incremental information reported in the footnotes to annual financial statements.

Munnell et al. (2010) consider the debate in the USA on the discount rate appropriate in valuing liabilities in State and local pension plans. While State and local plans generally follow an actuarial model and discount their liabilities by the long-term yield on the assets held in the pension fund, the authors contend that the widely held view of US economists is that the discount rate should reflect the risk associated with the liabilities and given that the benefits are guaranteed under most State laws, the appropriate discount factor is a riskless rate (typically below the yield that plans expect to earn on their investments and thereby resulting in a higher reported liability). The authors contend that using the return on a plan's assets to discount its liabilities produces misleading results. It assumes that the entire assumed yield on the assets is available to help pay future benefits and makes no allowance for the cost of expected losses, represented by the risk premium.

McNally and O'Connor (2013) found that the current legal and regulatory framework for Irish defined benefit pension schemes could result in three different valuations for a scheme at any particular point in time, each of which would be regarded as fully acceptable for its specific purpose and to its specific target audience. A valuation is required for IAS 19 purposes, for the purposes of determining whether the fund satisfies the minimum funding standard valuation set down by the regulatory authority and one is required for the fund trustees, for the purposes of their annual report to scheme members. The prescribed guidelines in each of the three valuation processes in themselves necessitate differing assumptions (including different discount rates), calculation bases, and different emphases in the produced results. The lack of cohesiveness between the three valuation models poses 
JFRC 27,1

difficulties for stakeholders endeavoring to comprehend the financial health of a pension scheme.

Brown and Pennacchi (2015) argue that there is an important difference between the appropriate measures of a plan's funding status and the appropriate measure of its market value. The authors contend that the appropriate rate for discounting depends on the purpose of the discounting exercise. In particular, if the objective is to account for pension under- or over-funding, a default free discount rate should always be used. If the objective is to determine the market value of an employee's pension benefits, then it is appropriate that discount rates incorporate the plan's default risk. The authors contend that the defaultfree discount rate is the relevant measure in establishing the amount of money the plan would need to be able to pay promised benefits or if the plan wished to offload, its liabilities to an insurance company that intends to make good on future benefit payments. He uses the example of General Motors who transferred its accrued pension liabilities to an insurance company who would then provide the retirement annuities to the sponsor's employees. The insurance company taking over the plan would require the sponsor to pay the difference between the accrued plan liabilities discounted at the default free rate and the plan's assets (plus administration costs), thus eliminating any risk for the insurance company in terms of the ability of the assets (including transfer price) transferred to meet the pension liabilities. The authors address the practical question of how to measure default free discount rates and find that Treasury yields are a reasonable approximation to a discount free rate.

Pension Industry reports recognize the volatility that IAS 19 reporting has introduced to the financial statements of quoted companies with DB schemes. Attain Consulting (2009) limited estimate that a 0.1 per cent increase in the discount rate can result in close to a 2 per cent reduction in scheme liability values depending on the nature and duration of the scheme's pension liabilities. Lane Clark and Peacock (2014) in their report on 16 of the largest Irish quoted companies (by market capitalization) and 13 semi-state/state-controlled companies with defined benefit schemes contend that the deficits of the schemes analyzed more than doubled between December 2013 and August 2014. Despite a gain of more than 12 per cent in global equity markets in the period, a fall in the bond markets over the same period had the effect of increasing total scheme deficits from $€ 4 \mathrm{bn}$ to $€ 8.5 \mathrm{bn}$.

Earlier versions of IAS 19 allowed some flexibility as to the recognition of certain actuarial gains and losses associated with defined benefit schemes, depending on their size relative to the overall assets/liabilities of the scheme. Recognizing that in the long term, actuarial gains and losses could offset each other, the "corridor approach" permitted sponsoring employers to defer immediate recognition of such gains and losses providing certain conditions were satisfied. The corridor approach accordingly achieved a "smoothing" effect in the reporting of scheme valuations. The "corridor approach" was however eliminated for accounting periods beginning on or after 1 January 2013 to achieve greater consistency in accounting for employee benefits by eliminating recognition and presentation options which had previously existed. The revisions also sought to provide more targeted disclosure requirements which would highlight the relevant risks of defined benefit plans.

\section{Recognizing the role of the hedge}

IFRS 9 Financial Instruments, which replaces IAS 39 Financial Instruments, sets out most recent developments in accounting practice for the recognition, measurement, impairment, de-recognition of financial instruments and general hedge accounting. The IFRS provides for situations where financial assets and financial liabilities may be recognized at fair value if doing so eliminates or significantly reduces a measurement or recognition inconsistency 
(sometimes referred to as an accounting mismatch) that would otherwise arise from measuring assets or liabilities or recognizing gains and losses on them. Similarly, S. 12 of FRS 102 whilst specifically excluding employer's rights and obligations under employee benefit plans, permits an entity to designate a hedging relationship between a hedging instrument and a hedged item when certain defined criteria are satisfied and so qualify for "hedge accounting." "Hedge accounting" provides that a financial asset and a financial liability shall be offset and the net amount presented in the SOFP when an entity:

Currently has a legally enforceable right to set off the recognized amounts; and intends to settle on a net basis, or to realise the asset and settle the liability simultaneously.

The prescribed discounting of pension liabilities as set down in IAS 19/FRS102 in situations where the trustees have actively sought to match the nature and duration of the scheme assets with the nature and duration of its liabilities, would appear to be at odds with this principle and could result in a significant "accounting mismatch".

Van Aalst et al. (1994) consider asset liability modeling for pension funds and derive a one-period linear factor model to describe the interest rate risk, inflation and real wage growth risk, actuarial risk and pension system risk of scheme liabilities. The authors contend that by estimating a similar factor model for different asset categories that are available, assets and liabilities can be matched using a mean variance approach. A number of key hypotheses underlie their conclusions. These are: fluctuations in the value or return of assets cannot be considered a risk as long as the value or return of the liabilities show a comparable pattern; conclusions about asset liability matching can only be useful when assets and liabilities are valued in the same way, and the liabilities of a pension scheme are the present value of the accumulated rights of the present (active and non- active) participants. New years of service and new participants are new events, which will have to be financed by new contributions at the moment of origin. As asset/liability matching models become more sophisticated and pooled funds investment strategies are developed to recognize key liability risks, the current position of IAS 19/FRS102 could be argued to be outdated.

\section{The true and fair override}

Ho (2016) documents a case study of true and fair view override in financial reporting by HSBC. The HSBC group recorded a 2009 rights issue to existing shareholders as equity, based on the economic substance of the transaction, notwithstanding that a strict interpretation of IFRS required the transaction to be recorded as a financial liability instrument because it was not in the functional currency of the issuing company. HSBC argued that a strict application of the accounting standards would have rendered the financial statements misleading and chose to depart from the requirements with a true and fair override. The author contends that because of political pressure from management and regulators, standard setters introduced stopgap measures to allow reclassification of certain financial assets and ultimately embarked on a three-year project to replace IAS 39 the "problematical" standard. However, the author accepts that it is very rare to apply the true and fair override, which relies heavily on professional judgement.

There was an alternative for HSBC, complying with IFRS and presenting the economic substance of the transaction by way or a note to the financial statements. The author believes that the management of HSBC did not consider this alternative as viable. This coincides with the findings of Coronado et al. (2008) discussed earlier, as to the relatively little weight that is placed on the incremental information reported in the footnotes to annual financial statements. 
JFRC 27,1

\section{Economic decision-making and IAS 19/FRS 102 presentation}

There has been a definite move in recent years by defined pension schemes to reduce stock market risk and protect earnings by purchasing Government and sovereign bonds (by the end of 2016, approximately 40 per cent of Irish fund pension fund assets were invested in equities and approximately 37 per cent were invested in Sovereign bonds). This compared with a close to 65 per cent investment in equities at end of 2005 (IAPF, 2006, 2017). This coincides with an increased focus by trustees on asset/liability matching or liability driven investment (LDI) to reduce the funding risk ratio within the investment strategy.

Table I demonstrates the IAS 19/FRS102 treatment of a mature pension fund investment in sovereign bonds with maturities matching 100 per cent of a portion of the funds liabilities. If we assume that both the assets and liabilities in this example have the same interest rate sensitivity, from the trustees' perspective, this is an ideal scenario. The financial statements of the sponsoring company however, present a very different picture. This is because the financial statements measure the fund liabilities by reference to the prevailing AA corporate bond rate rather than the hedged rate i.e. the applicable sovereign bond rate.

In the example set out in Table I, the IAS 19/FRS102 required treatment results in fluctuating valuations for the scheme (surpluses and deficits) over the 10-year period under review. This is notwithstanding the hedged position of the scheme liabilities. Table II demonstrates the impact of the fluctuating valuations on the reported reserves of the sponsoring company for the period under review. In the scenario presented, the deficits/surpluses presented could not be regarded as having predictive or confirmatory value. Recognizing the hedged position by discounting both scheme assets and liabilities at the hedged rate would provide more relevant information and a more faithful representation of the ultimate position of the scheme at maturity. It is recognized that schemes may not wish to or be in a position to hedge all scheme liabilities but may hedge part or blocks of liabilities. However, recognizing the value of the "partial hedge" in calculating the overall surplus or deficit in the sponsoring company's financial statements would in itself be informative in that the user of the financial statements could then correctly interpret that the surplus or deficit as presented referred to unhedged liabilities only.

As demonstrated in Tables I and II, in times of high corporate bond volatility, as has been the case in recent years, the financial statements of the sponsor could year on year show a fluctuating surplus or deficit pertaining to the pension fund, notwithstanding the reality of its hedged position. How might this potentially affect economic decisionmaking? It presents difficulties in interpretation of the financial statements for users including investors, potential investors and providers of funding and creates significant headaches for investor relations departments of international corporates, in terms of the explanations, which may be required. Ultimately a sponsoring company could decide to move its pension liabilities effectively "off Balance Sheet" by transferring the related hedged assets and liabilities to an insurance company (similar to General Motors). In a hedged situation, insuring pension liabilities has the effect of reducing the volatility of the SOFP at a cost, which presumably should equate to an administration fee. The net effect of insuring pension liabilities in this way would be to reduce the impact of the pension fund on the sponsoring company financial statements to an annual charge equivalent to the net insurance premium payable to insure the pension liabilities. Companies might be willing to incur the extra costs to avoid financial statement 


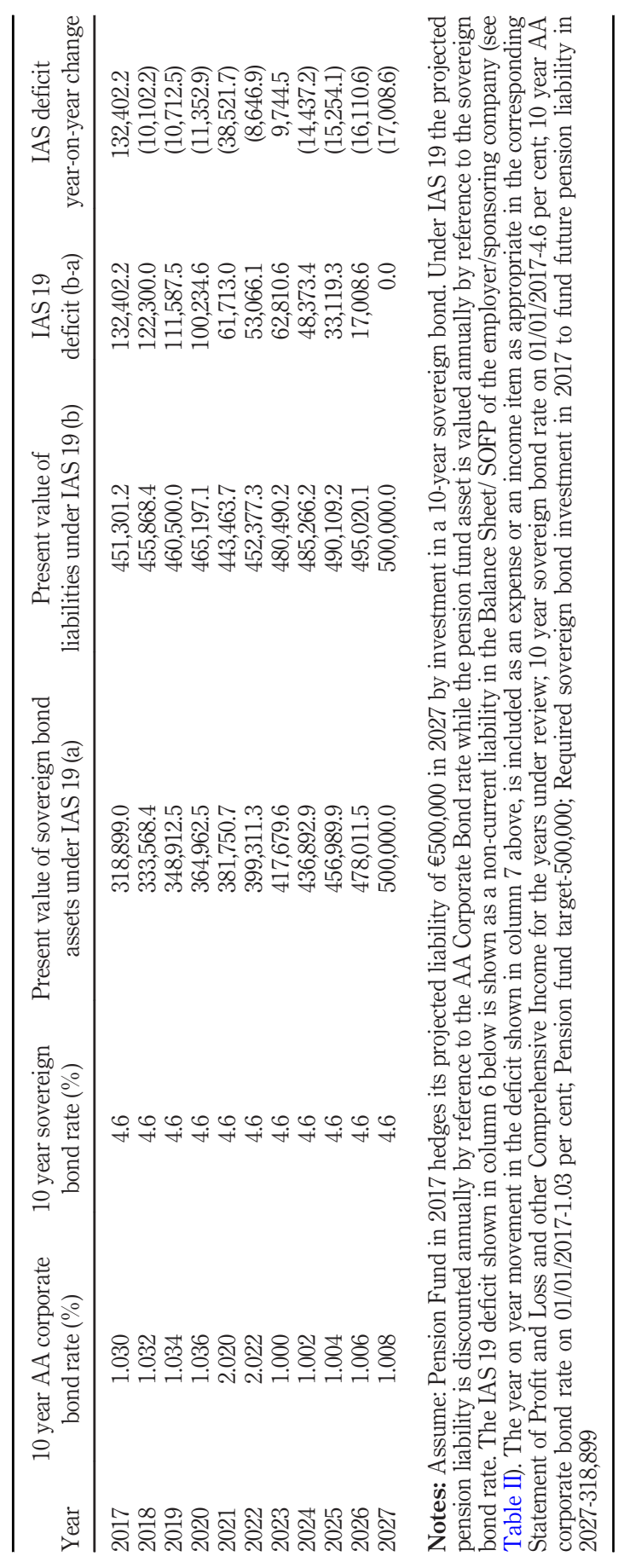

Table I.

The valuation of a pension scheme under IAS 19/ FRS102 where the scheme has hedged its liabilities by investing in sovereign bonds with matching maturity amounts 
JFRC

27,1

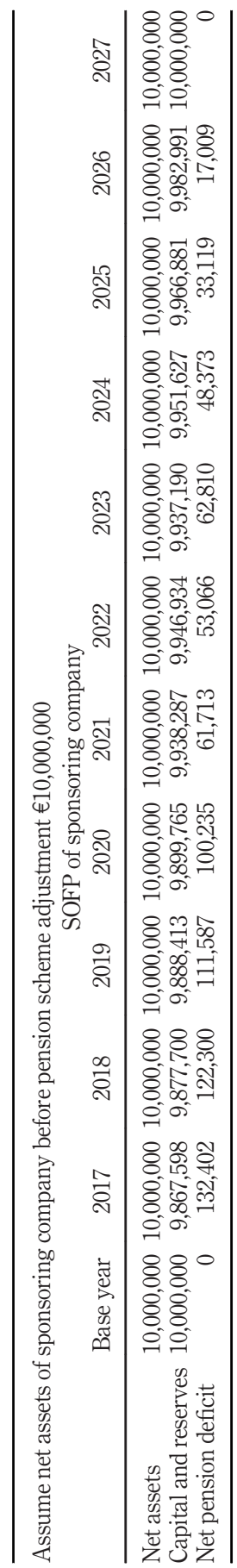

Table II.

The statements of financial position/ balance sheets of the sponsoring/employer company based on the valuation results presented in Table I 
volatility. This would in turn have consequential effects for the underlying pension Defined benefit scheme and its modus operandi.

\section{Concluding remarks}

The IAS 19/FRS102 requirement to discount actuarial liabilities by reference to AA corporate bond rates gives rise to anomalies in Financial Statements reporting particularly where the underlying pension scheme has embarked on a program of hedging its liabilities with assets of fixed return maturity dates. The underlying objective of accounting standards local and international that financial statements provide information, which is useful and relevant to decision-making, is thwarted if the reported pension surplus or deficit is calculated without reference to the hedging strategy adopted. It necessitates disclosures over and above the reported numbers in the financial statements if interested parties are to fully understand the investment strategy of the underlying pension scheme and research has shown that these disclosures are not as influential to potential investors as the reported numbers. Companies could ultimately decide to insure pension liabilities to remove the volatility of IAS 19 reporting with consequential medium to long-term effects for the pensions industry as a whole. It calls for a reevaluation of the rigidity around some of the provisions of IAS 19 given the potential complexities around "over-riding" the IAS.

\section{References}

Attain Consulting (2009), “Accounting for pensions in Ireland, part 2 - don't discount the discount rate", available at: www.atain.ie

Brown, J.R. and Pennacchi, G.G. (2015), "Discounting pension liabilities: funding versus value”, NBER Working Paper No. 21276.

Coronado, J., Mitchell, O., Sharpe, S. and Blake Nesbritt, S. (2008), "Footnotes aren't enough: the impact of pension accounting on stock values", Journal of Pension Economics and Finance, Vol. 7 No. 3, pp. 257-276, doi: 10.1017/S147474720800379X.

Ho, H. (2016), "A case study of true and fair view override in financial reporting", Nang Yan Business Journal, Vol. 5 No. 1, pp. 13-19.

IAPF (2006), Asset Allocation Survey 2005, Irish Association of Pension Funds, Dublin.

IAPF (2017), IAPF Pension Investment Survey 2016, Irish Association of Pension Funds, Dublin.

International Accounting Standards Board (2011), IAS 19, Employee Benefits, IASB, London.

Khorasanee, Z. (2004), "What discount rate should be used to value defined benefit pension liabilities", The Pensions Institute Discussion Paper 0402.

Lane Clark and Peacock (2014), "Pensions accounting briefing 2014", available at: www.lcpireland.com/ news-and-publications// (accessed 7 November 2016).

McNally, B. and O'Connor, T. (2013), "Actuarial valuation of pension schemes: an Irish perspective", The Accounting, Finance and Governance Review, Vol. 20, pp. 45-71.

Munnell, A.H. Kopcke, R.W. Aubry, J.P. and Quinby, L. (2010), "Valuing liabilities in state and local plans, state and local plans issue in brief 11", Centre for Retirement Research at Boston College.

Van Aalst, P.C., Guus, C. and Boender, E. (1994), "Asset liability matching for pension funds: a one-period model", in Peccati, L. and Virén, M. (Eds), Financial Modelling: Contributions to Management Science, Physica-Verlag HD, Heidelberg. 


\section{Further reading}

Financial Reporting Council (2013), FRS 102: The Financial Reporting Standard Applicable in the UK and Republic of Ireland, IFRS Foundation, London.

International Accounting Standards Board (2010), Conceptual Framework for Financial Reporting, IASB, London.

International Accounting Standards Board (2014), Financial Instruments, IASB, London.

Corresponding author

Bridget McNally can be contacted at: Bridget.McNally@mu.ie

For instructions on how to order reprints of this article, please visit our website: www.emeraldgrouppublishing.com/licensing/reprints.htm

Or contact us for further details: permissions@emeraldinsight.com 